\title{
Satellite imagery and the spectacle of secret spaces
}

\author{
Chris Perkins*, Martin Dodge \\ Geography, School of Environment and Development, The University of Manchester, Oxford Road, Manchester M13 9PL, UK
}

\section{A R T I C L E I N F O}

\section{Article history:}

Received 3 July 2008

Received in revised form 27 April 2009

\section{Keywords:}

Secrecy

Spectacle

Satellite imagery

Power

Counter-hegemony

\begin{abstract}
A B S T R A C T
This paper documents and assesses emerging efforts to resist and subvert deep-seated and long-held governmental secrecy over geographical spaces of military/security activities and other sites deemed sensitive by the state. It explores tensions in new web-served mapping and high-resolution imagery of these sites, which view them though 'pin holes' of publicly available data. These 'counter-mappings' focus attention on the significance of sites that are either buried unnoticed in seamless global image coverage, or else censored on official mapping. Some reveal a tenaciously anti-hegemonic and oppositional discourse, others a more playful set of cultural practices, one that ridicules as much as directly resists. We situate these newly witnessed secret sites in contemporary visual culture, exploring the spectacular and Debordian possibilities of resistance that they offer, and evaluate the significance and ironies of these diverse imaging practices.
\end{abstract}

(c) 2009 Elsevier Ltd. All rights reserved.

\section{Introduction}

"Secrecy has become integrated into (no longer expelled from) the spectacle; forming a spectacular secrecy... This spectacular form generalizes secrecy into public and private domains, making revelation no longer the end to secrecy, but its new catalyst" (Bratich, 2007, p. 42).

Secrets are strongly associated with visual culture: they are hidden from view but may be revealed; ubiquitous, but often unseen and are particularly associated with certain spaces. This paper focuses upon the role of satellite imagery in the contestation of sites deemed secret by nation-states.

Secret spaces cover a wide range of places and facilities, including a panoply of military installations, sites relating to state security, policing and prisons, and increasingly 'strategic' national assets and infrastructures (particularly nuclear facilities). These are often hidden to some degree from civil society, and protected by legislation, as well as being physically separated by 'keep-out' signposts, high fences and patrolling guards. All nation-states operate systems to protect their security, and many of these systems depend upon keeping critical information relating to location, operations and internal layout hidden, from citizens or outsiders, who might threaten the hegemony of those who rule. Woodward (2005) for example draws attention to the ways in which military activities are ubiquitous but unseen in the fabric and processes of everyday British life. In the post 9/11 world perceived geopolitical 'threats' have strongly encouraged many states

\footnotetext{
* Corresponding author.

E-mail address: c.perkins@manchester.ac.uk (C. Perkins).
}

further to restrict information in the public domain, and also to try to use a range of surveillance technology in more adept ways of controlling their citizens and outsiders. Secrecy is now ubiquitous in global culture (Birchall, 2007). But these same technologies of control also allow the formerly secret to be seen for the first time by civil society, and notions of being secret or open are complex and contested.

This article focuses upon the tensions represented in the witnessing of these secret sites, by assessing the significance of different kinds of imaging of these places on the web. Tensions around national security, freedom of information, confidentiality, neo-liberal accumulation, regulation, technology and representation are considered and contested in this process. Here, we investigate the interface between strategic deployments of visual technologies of mapping, aerial photography and, in particular, high-resolution satellite imagery that has traditionally concerned geographers. Our argument starts by exploring the customary and exclusive 'official' uses of mapping and overhead imagery, and their theorisation as strategic and rational tools of governance. Tropes of mapping for social control are, we argue, being increasingly destabilised, and part of this process has been encouraged by the increasing availability and dissemination of high-resolution imagery via the internet. We argue, however, that a more complex reading of secrecy is needed to understand this process and then illustrate possibilities of counter-hegemonic re-imaging of what is supposedly secret, in a comparative case study of three contrasting webbased activist projects, exploring the contextual differences, how these relate to Guy Debord's (1998) notions of 'spectacular secrecy' and to changes in what might be deemed 'secret' in western society. 


\section{Seeing as control}

Seeing casts a particular power: it reveals the hidden, conveys precision and offers control to the observing eye. An elevated vision can appear to be a 'view from nowhere' (Haraway, 1988) and overhead satellite imagery as media has been closely associated with scientific and managerial approaches to the world (Parks, 2001; Robbins, 2003). Connotations of a naturalistic objectivity and transparency flow from the use of these visual technologies: the aesthetic of abstraction and remoteness connotes the image as a document of truth, and hides the political work the image is employed to achieve. Military and state strategic interests derive much of their power from this naturalising surveillant capacity that denies the humanity of landscapes seen. However, regarding these images from space as neutral, mirror-like 'views from nowhere' has been shown to be deeply naïve. As Wood and Fels (2008) insightfully detail, imagery is no less neutral than the culturally tainted map text. Images are embedded in situated, cultural contexts (see for example the very different roles played by imagery discussed in Parks (2009) and Aday and Livingston (2009)).

The militaristic logic of state institutions such as the police, security services and intelligence agencies rests in large part on their ability to render spaces and subjects visible, without the surveilled knowing when or why they are being watched (Pickles, 1991). The success of this strategy rests, in large part, upon exclusive control of these data. In the history of modernism, mapping technologies are acknowledged as the militaristic gaze par excellence because of their ability to survey extensive areas and render complex landscapes into standardised, fixed, addressable and knowable visual symbols (Pickles, 2004). Large-scale national topographic surveys commissioned throughout Europe from the eighteenth and nineteenth centuries and extended to European colonies were established primarily to help military forces to maintain state control over territory. State mapping agencies almost all trace their origins to military needs and the cartographic specifications underlying most contemporary national 'framework' geospatial data-sets are derived from the needs of war fighting (Parry and Perkins, 2000). McHaffie (1995) highlights ongoing links between public and private mapping sectors and the military in the post-war period in the United States and civilian and commercial interests were strongly associated with military funded research and development during advances in geo-spatial technologies in the Cold War period (cf. Cloud and Clarke, 1999; Mack, 1990). Many of these advances were driven by the need to extend the range, rapidity and diversity of this military visual capacity (Day et al., 1998; Monmonier, 2002). Global positioning system technology was initially developed to facilitate more accurate targeting of weapon systems and despite its growing civilian application, it is still under the command of the US military. Similarly, the development of GIS has been strongly influenced by rounds of military investment during the Cold War (Cloud, 2002; Pickles, 1995).

The technologies that are most significant for our argument here, however, concern the collection of visual data, and stem from developments in photogrammetry and remote sensing. Indeed, the scope of visibility over space granted by conventional cartographic representations has in many senses been surpassed over the last fifty years by the availability of aerial photography and satellite monitoring. Such remotely sensed data have seen progressive increases in spatial and temporal resolution, and they form a critical part of the military 'surveillant assemblage' (Haggerty and Ericson, 2000), defined by Harris (2006, p. 118) as "a set of heterogeneous imagery, intelligence, and command systems and architectures whose unity is derived from their transparently smooth interoperation." The specifications of the original Landsat satellite sensors were driven by military needs (Mack, 1990). Global imagery in
GIS are all ultimately derived from data captured as a side effect of military space imaging technology (Roberts and Schein, 1995). Military spy satellites amassed huge quantities of 'secret' imagery during this period (Richelson, 1998), and geospatial surveillance systems now form an essential part of the armoury of security agencies in the 'war against terror' (e.g., Beck, 2003). Imagery was used to build evidential pictures that proved critical to support the case for the Iraq war in 2003 (Richelson, 2003). Subsequent security applications include identifying possible sites of nuclear threats in Iran and North Korea. Unsurprisingly the largest demand for commercially available high-resolution imagery is from military and intelligence agencies in countries without their own spy satellites (Dehqanzada and Florini, 2000).

We would therefore assert that the most effective mapping and imagery, in terms of coverage, scale, positional accuracy and currency, has been, and often still is, the exclusive preserve of the military, and the strategic advantages this brings have been jealously guarded by those in power.

\section{Hegemony, counter-mapping and satellite imagery}

It has been argued that modern states maintain hegemony not by direct use of force, but rather because their citizens are prepared to accept inequality and injustice, reflected in political, cultural and social norms and institutions (Gramsci, 1971). Gramsci's notion of hegemony depends on the existence of an accepted ideology that serves the interests of a dominant elite, but one that is also taken for granted in everyday social and cultural practice, and reflected in the existence of normalised meanings attached to institutions, discourses and representations. Counter-hegemonic strategies can challenge dominant social forces by arguing for a platform of action to disrupt hegemonic cultural norms, and in so doing 'countering' dominant discourses and offering a challenge to the ongoing mechanics of state power. Williams (1977) recognised that these alternatives might co-opt or compromise existing power, as well as explicitly countering its operation: emergent ideological alternatives need not explicitly challenge, or oppose orthodoxy. Thus opposition to hegemony might take many forms, including establishing new discursive frames, enabling new spaces for political action, encouraging legal or political reform, or enacting alterative social practices or institutions (Mouffe, 1999). We believe counter-hegemony should be thought about as encompassing "a multiplicity of voices" and having within it all "the complexity of the power structure that this network of differences implies" (Mouffe, 1999, p. 757). Recent interventions into this debate have suggested an increasing complexity of oppositional voices facilitated by the web and internet-based communication: cultural and political challenges increasingly take the forms of 'jamming', subverting by reworking an establishment form into something new (Cammaerts, 2007). These tactics and actions typically poke fun at corporate values, social norms and government hypocrisy and are intended to influence attitudes or behaviours, by making people think differently, or look at a space from a new perspective.

There has so far been little research that explicitly considers how these notions of counter-hegemony might relate to the artifacts, practices and discourses of visual culture. Nevertheless some truly anti-hegemonic mapping, able to challenge power relations by highlighting social inequalities, has grown apace in the last twenty years (Harris and Hazen, 2005). Published maps can embody a practical and rhetorical power to articulate alternatives. These alternative representations can be used to re-frame the world in the service of progressive interests and challenge inequality (see for example Bunge, 1971). They have been used to reaffirm the rights of indigenous peoples; argue local cases in resource struggles; confront globalisation and multinational power; 
encourage community involvement in sustainable lifestyles; reassert the role of the past in contemporary contexts; or celebrate the aesthetic and local in an age apparently dominated by uniform and mechanised production and global style (Perkins, 2006).

There is a long history of counter-hegemonic mapping. Pinder (1996) for example shows how Debordian situationist practices in Paris in the 1950s sought to re-imagine a utopian urban condition, by deploying existing maps in novel ways to problematise the order of capitalist accumulation. Mapping practice could itself become playful instead of controlling: people could move through the city in dérives, performing spaces differently and making new maps.

The satellite image may also be re-imagined and subverted. Imagery may be used in artistic works: to reassert the beauty of abstracted landscapes, or to problematise the apparently all-knowing nature of satellite-based surveillance and reveal the bodily practices denied in the objectified military image (see Biemann, 2002; Litfin, 1997). Like other counter-maps these reworkings of remotely sensed imagery often only offer limited visual enhancements to existing imagery. It is through techniques of highlighting, juxtaposition, labelling and conscious cross-linking to other dissonant sources that a different political message is communicated.

Cartographic power has also been exploited to counter dominant corporate discourses, using the authority of the map against itself (see for example Mogel and Bhagat, 2007). This redeployment, or détournement, involves what Vidler (2006, p. 14) describes as "using the enemy's material against itself." A Debordian approach to counter-mapping recognises this ambivalent potential of creating new images from existing visualisations. Revealing secrets by mapping them has been cast by some as a kind of situated and 'reverse-panoptical' discourse, in which the taken-for-granted neutral power of satellite imagery, aerial photography and mapping is deployed against the very forces that were instrumental in its original deployment (see Natsios and Young, 2001 for a consideration of this concept). It can be argued that changing technologies of representation, and especially shifts in the spatial resolution and availability of high-resolution satellite image data are facilitating these counter-maps.

In a wider context many aspects of national government and corporate activity appeared to operate in a more transparent fashion in the new international political structures that emerged in the 1990s after the fall of the Berlin Wall. The demands of international trading and trans-national interactions in a globalising world drove calls for more open government and greater corporate social responsibility. Florini (1998, p. 53) argues that "the world is embracing new standards of conduct, enforced not by surveillance and coercion but by wilful disclosure: regulation by revelation". International bodies and NGOs audit press freedom in different countries, 'score' corporate ethics and environmental conduct, and tabulate government corruption. Meanwhile an increasing number of governments have enacted freedom of information legislation (Banisar, 2004).

A small, but significant, element in these new mechanisms of more open governance stemmed from the apparent transparency offered by commercially-available high-resolution satellite imaging (Baker et al., 2001). Livingston and Robinson (2003) argue that state regulation of high-resolution imagery is now impossible given the diffusion of the technology beyond the confines of US legal jurisdiction and military power. In the years since the end of the Cold War there has been a significant switch from detailed satellite imagery that was previously secret and the exclusive preserve of military-intelligence, to a much more global and commercial environment. By 2007 thirteen different countries had mid-to-high resolution optical systems in orbit and by the end of the decade there will be twenty-one (Stoney, 2008). The commercial market is currently led by Space Imaging's Ikonos and DigitalGlobe's Quickbird satellite platforms, providing imagery at sub-metre resolution. Mass-market access to data from these systems is increasingly dominated by web portals such as Google Earth, which serves imagery in virtual globes. Multinational corporations like Google offer, in some senses, mechanics to subvert military hegemony over global scale mapping and imagery and the next generation of satellite imaging platforms will yield even more detailed and sophisticated visual evidence.

Some commentators argue the unprecedented spatial detail, currency and availability of these data create the possibilities of almost utopian change with more equal, democratic access to overhead vision in which "[n]onstate actors will be able to peer behind the walls of national sovereignty, accelerating a shift in power that is already under way" (Dehqanzada and Florini, 2000, p. v). And Baker and Williamson (2006, p. 4) note the rise of what they term 'imagery activism' by NGOs, academics, researchers and the news media that "help focus domestic and international attention on problematic issues such as environmental degradation, international security and human rights abuses in closed societies."

It is undoubtedly true that the pictorial value of high-resolution satellite imagery has advantages over the topographic map, particularly in communicating to the general public. The photographic quality of imagery data means familiar features are often easily recognisable and the image exudes an apparent naturalness. In many respects images also have an aesthetic appeal above the functional abstraction of topographic mapping. These affectual qualities, the politics behind which images are used, and how they are interpreted alter their rhetorical force and counter-hegemonic significance (cf. Parks, 2009).

An increasing range of actors is now able to deploy imagery, for example in disaster relief, managing refugees, supporting peacekeeping missions, protecting human rights, or monitoring compliance with international treaties (cf. Baker et al., 2001; Baker and Williamson, 2006; Dehqanzada and Florini, 2000). These different groups use satellite data to articulate opinions that sometimes reinforce the hegemony of nation-states, but often they advance counter-hegemonic views, which challenge accepted cultural norms. Whilst independently sourced, verified and interpreted satellite imagery has the power to puncture state propaganda and shift public opinion, the context in which it is produced, released and read is crucial and impacts strongly on the kind of counterhegemonic challenge it offers. For example Parks' (2001) analysis of the use of satellite images of Srebrenica in 1995, during the Bosnian conflict, shows how the officially-released US military images of mass graves focused attention on the cultural power of the satellite image. The US military delayed releasing the images until after the event, as part of a strategy of deception, which embodied a careful 'oversight' of the massacres as part of a distancing strategy. The only large-scale images released in the conflict 'revealed' the mass execution of Muslims, and served to condemn Serb aggression, whilst justifying the lack of action to prevent the massacre. The television news anchors described the images as evidence, but complex narration and graphics were used to 'ground the orbital gaze'. Parks argues, therefore, for a witnessing process in which the use of satellite imagery must inevitably be questioned and in which the abstraction, construction and politics of the image is revealed. Detailed satellite images are ideal for television reporting because they purport to be able to 'show' the audience the reality of news: in practice the satellite view is disembodied, partial and clearly positioned. The news media may appear to deploy the image to critique state policy, in practice they may be used to support a more complex rhetoric, part of a commercial battle for ratings.

So satellite imagery appears seductively complete, but total oversight masks variable data quality and the difficulty of ascribing meanings to what is seen on the ground. Commercial and technological forces for greater access are in tension with security 
concerns: those in power still carefully manage access to visual culture. In practice the apparent binary divide between what might be seen as publicly available, and what might be secret becomes crucial, and counter-hegemonic potential depends on the everyday practices of secrecy.

\section{Secrecy and spectacle}

"[O]fficial map-making agencies, usually under the cloak of 'national security', have been traditionally reticent about publishing details about what rules govern the information they exclude especially where this involves military installations or other politically sensitive sites." (Harley, 1988, p. 306).

A commonly accepted definition of secrecy sees it as the practice of selectively sharing information, but at the same time hiding it from certain groups. Of course this simple definition ignores the context in which the term operates: a personal secret carries connotations of intimacy and privacy, whereas something which a government keeps secret focuses attention to a much greater degree on national hegemonic power. In this official context secrecy becomes the obverse of publicity, demonised by many who value open government, and carrying many negative connotations: a box that should be opened. Legal mechanisms are required for keeping secrets, and power needs to be exercised to regulate what can circulate in the public realm (Ku, 1998). So any campaign for increased openness, for publicity, becomes a political struggle. Censoring of information is the mechanism for maintaining secrecy - state agencies, the mass media, civil and community groups, activists and academics, and private corporations all engage in processes of selectively revealing or concealing information, suppressing or deleting material that they deem to be sensitive, harmful to their agenda, or merely embarrassing to people in power. Maintaining secrecy frequently involves hindering access to information that might threaten hegemonic power. For example, hiding the geographical location of a site or activity makes it harder for oppositional forces to contest or argue about the reasons for its existence. Secrecy itself has a strategic spatial power.

The overt or hidden visual representation of the secret is rather different from other aspects of keeping secrets, and is best understood in the light of a cultural understanding of the role of visual practices (Rogoff, 2000). The visual carries different connotations to the linguistic, and mapping and imagery themselves are read in very specific ways, as icons of fact, standing for disembodied objectivity. In the world of military and state security, regimes of secrecy relating to spatial information are required to hide this 'objective' information so that it becomes un-verifiable for those who do not have access to it. This has conventionally been achieved by cloaking military mapping and intelligence data gathering with national security blankets. There are many strategies for keeping the cloak on: product specifications for mapping or imagery may elide whole categories of information, and freely available public imagery almost always only displays visible wavelengths, whilst official access exploits data available across a much wider range of the electro-magnetic spectrum; information is guarded and classified (e.g. the orbits of military spy satellite are kept under wraps); maps and images in the public domain omit 'secret' detail; information is deliberately falsified, or obfuscated; or the existence of mapping as a whole is denied.

Regimes of state-mandated cartographic secrecy are as old as the nation-state itself. Harley (1989) shows how the Casa de la Contración maintained the Padron Real in the early sixteenth century as a secret master map to protect the key discoveries of Spanish explorers. In times of conflict mapping is a closely guarded secret, deployed as a weapon to clarify the fog of war for friendly forces, but also as an obfuscatory tool to confuse the enemy. From Napoleonic battle plans, to secret trench maps of the First World War and now in the so-called 'war against terror', military strategy is played out through mapping or deceptively hidden from the cartographic gaze.

A wide range of intentional and deliberate 'silences' on civilian maps is most associated with security paranoia of totalitarian regimes (e.g., Postnikov's, 2002, study of cartographic deceptions in the Soviet Union). However, such 'silencing' practices deployed to preserve the secrecy of security apparatus are not limited to closed states. Throughout the Cold War military bases, nuclear and civil defence infrastructure and security installations were absent from large-scale topographic maps in a number of liberal democracies, including Ordnance Survey mapping in Britain (see Hodson, 1999, pp. 157-168). Published aerial photographic coverage of a range of sites across the UK was also frequently doctored to hide what were deemed to be sensitive details (Board, 1991). Withholding of information, in part so as not to unduly alarm the general public about the consequences of a nuclear attack, also served to cover extravagant expenditure (Hennessy, 2003).

In the aftermath of $9 / 11$ there was a resurgence of fear about the security of military sites and other "critical national infrastructures' that led to calls to limit the open distribution of detailed geospatial data. Zellmer (2004) explores many examples of US federal government agencies withdrawing spatial data relating to these infrastructures from websites in this period, citing for example the removal of nuclear facilities from the Geographic Names Information System and the National Atlas of the United States. Strategic buildings such as the Pentagon were suddenly no longer visible on the MapQuest aerial photo database (Monmonier, 2005). Late in 2001 the US Department of Defense purchased exclusive rights to Space Imaging's Ikonos coverage of the early phases of the war in Afghanistan in an attempt to maintain control over the public policy debate (Livingston and Robinson, 2003). Despite subsequent recognition that very few data sets pose significant threats, the balance between social benefits of freedom of information and the demands of 'homeland security' had shifted and there is now a wider definition of 'sensitive sites' (to include infrastructure networks, water supply systems and nuclear power stations), and continuing restrictions on some data (Tombs, 2005).

The growing deployment of remotely sensed imagery in GIS has also been subject to the dictates of official secrecy. The extent of commercially available data described in the previous section challenges military operational security: an enemy can now acquire data on the international market that might, arguably, compromise military action. For example, in 2006 Iraqi insurgents reportedly used Google Earth to 'spy' on the layout of British bases in Basra (Harding, 2007), leading to Google 'censoring' its own data by substituting outdated imagery of the area (Haines, 2007). Security agencies in many countries seek to influence the content of publicly available images.

It is tempting to read these restrictions as a rearguard action in the face of technological change and as a response to the 'New Normal' in a world destabilised by economic uncertainty, terrorism and global fears of contagion ${ }^{1}$. However secrecy is a complex social construct, with connotations well beyond notions of just 'keeping the box shut', and well beyond a simplistic opposition between being secret or open. Deleuze and Guattari (1987, pp. 286-290) argue secrecy may indeed be seen as a container, but is also a series of actions and perceptions. It is a social process. Dean (2002, p. 10) also argues that "[t]he actual contents of any secret are therefore

\footnotetext{
${ }^{1}$ The term 'New Normal' was first deployed in a 2001 speech by the then US Vice President Dick Cheney.
} 
immaterial. The secret is a form that can be filled in by all sorts of contents and fantasies - economic secrets, military secrets, sexual secrets, secrets to power, wealth, and immortality. Thus what is at stake is not content but connection, the relationship within and between communities held together and apart within a matrix of secrecy and publicity".

This social reading of secrecy is particularly richly developed in the work of Guy Debord. Debord (1967) critiqued the operation of consumer capitalism, theorising it as a society in which the real had been supplanted by the constant parade of images, visual spectacle and reified by social practice. Debord (1998) distinguished concentrated forms of spectacle characteristic of societies with strongly developed bureaucratic systems, such as fascist or communist states, from diffuse forms associated with advanced capitalist modes of accumulation. He argued that an integrated form of spectacle, in which specialist and secret knowledge is used to police the validity of social norms, characterises western liberal democracies. Spectacular secrecy comprises an increasingly visible culture, in which the secret becomes an everyday practice, necessary for the successful operation of consumer capitalism and state hegemony. Debord (1998, p. 12) argues that what he terms "generalised secrecy" stands behind the spectacle of contemporary society, which he believes represents "the decisive complement of all it displays and, in the last analysis, as its most important operation".

So an obsession with secrecy as a box to be opened, and as the dark side of publicity, distracts us from the necessarily hybrid nature of both, from the ubiquity of rumour, conspiracy, leaks, off the record briefings, spin, influences, and from what Bratich (2006, p. 494) identifies as "a whole host of agents trained in promoting spectacular secrecy". Developing this argument, Bratich (2006, p. 498) suggests that secrecy has become so ubiquitous that "we see not just an increase in public secrets, but an increasing monopoly over secretion or generalized secrecy". For Bratich (2006), official disclosure becomes a kind of strategy for managing public perception and shaping media agendas, instead of a democratic discourse. Secrets are everywhere, and even when they are revealed secrecy remain a powerful force.

The strategic nature of secrecy, however, reveals how other social forces can also deploy its power. Secrecy can itself be re-circulated; oppositional forces and dissidents can deploy secrecy to invent new safeguards and refuges, and different securities from those defined by the state. Resistance itself can take the form of making new kinds of secrets (Bratich, 2007). New modes of access to high-resolution satellite imagery, for example, can set out their own newly secret knowledge. Technological change facilitates this shift of secrecy from the shadows into the spotlight. The internet as medium is significant in this shift because of its apparent ability to 'super-empower' individuals and small groups to reach across scales and connect with mass audiences, and as such is playing an important role in the dissemination and sharing of alternative views and representations. There is strong evidence that the web is enabling rapid circulation of images and their interpretation, often unmediated by hegemonic forces of the state or large corporations. This democratisation of access can impact on powerful institutions that prefer to work hidden from public view. The emancipatory potential of the internet as a site for globalizing local resistance has, however, been a source of significant debate over the last decade (e.g., Warf and Grimes, 1997; Pickerill, 2006). The military and state security-intelligence apparatus, in particular, continuously struggle to deflect scrutiny from online activism. For example, the activities of satellite watchers who share technical information about the orbits of 'secret' satellites to reveal something of their purpose (Keefe, 2006); to the 'leakage' of photographs of prisoners being tortured by US soldiers in Abu Ghraib prison in Iraq; to plane spotters across the world logging flight patterns and helping to expose the secret CIA program of extraordinary rendition (Paglen and Thompson, 2006), what begins to emerge is a kind bricolage of counter-mapping of secret state operations based on a collective, crowd-sourced ${ }^{2}$, and amateur gaze, that is concurrently fiercely opposed by establishment forces.

We have seen that the dominance of military and state control over visual technologies is being actively denuded and secrecy apparently challenged by contemporary technological developments in the capture, processing and dissemination of satellite images, at the very time when spectacular secrecy is gaining ground. Meanwhile in fragmentary, small and subtle ways, which together perhaps constitute a significant trend, new visual routes to democratic scrutiny and the active witnessing of state and corporate power are being made, by re-mapping secrets, in a new 'jamming' process. These counter-mapping projects use the power of maps and satellite images in ways that subvert, instead of supporting the interests of elite groups.

The remainder of this article focuses attention on three contrasting 'counter-imaging' projects that use the web to deliver focused and annotated access to high-resolution satellite imagery and in so doing reveal some of the secret spaces of the state. We argue however, contra to Natsios and Young's (2001) notion of reversing the panoptic gaze, that these projects are apposite examples of spectacular secrecy. Their very existence depends upon the culture of secrecy, they create new kinds of secret knowledge and court publicity, and they embody an ambivalent and varying politics of resistance in their use of imagery.

\section{Revealing the secret site: case studies}

Systematic counter-mapping projects offer a contrasting view onto government secrecy, rendering hidden military bases and security installations visible once more. The following three case studies are chosen to reveal the situated nature of these oppositional (re)viewings, and highlight the need to view much more than just the image. These three web-based projects each deploy remotely sensed imagery, but focus the viewer's attention onto specific sites, instead of simply serving a global coverage. Each targets sites that are available on image and map sources in the public domain, drawing attention to the existence of particular facilities. They also juxtapose the image with other media, inviting critique of official secrecy, denials and blank spaces. We would argue following Wood and Fels (2008) that a map or image is always read in the light of its immediate context. Table 1 summarises some of the relevant attributes of the context of these counter-mapping projects: they differ in motivation, institutional context and content; they map different numbers and kinds of site, with varying geographic and temporal emphases; they also depict sites at different spatial scales and deploy imagery from different sources; the level of interpretation associated with the imagery, the extent of cross referencing, and outside linking and usability also varies.

We develop this contextual reading below, describing the nature of each project, before evaluating their wider cultural significance and relating them to changing conceptions of secrecy. We argue they each in different ways may be understood as illustrating the play of spectacular secrecy (Debord, 1998) and the potential of counter-hegemonic geographic visualisation.

\footnotetext{
${ }^{2}$ Crowd sourcing describes a supposedly new model of online information authorship premised on mass participation, distributed voluntary effort and loose coordination (Howe, 2006). It stands in contrast to traditional modes of centralised production undertaken by paid employees of institutions working to predetermined specifications.
} 
Table 1

Summary of counter-mapping projects.

\begin{tabular}{|c|c|c|c|}
\hline Name & Public Eye & Eyeball Series & Secret Bases \\
\hline Web location & $<$ www.globalsecurity.org/eye > & $<w w w . e y e b a l l-s e r i e s . o r g>$ & $<$ www.secret-bases.co.uk> \\
\hline Authorship & John Pike, security commentator and activist & $\begin{array}{l}\text { John Young, architect and anti-secrecy } \\
\text { activists }\end{array}$ & Alan Turnbull \\
\hline Start date & 1995 & 2002 & 2003 \\
\hline \multirow[t]{2}{*}{ Motivation } & $\begin{array}{l}\text { To offer intelligence-style photo- } \\
\text { interpretation of high-resolution satellite } \\
\text { imagery of military and nuclear sites }\end{array}$ & $\begin{array}{l}\text { To document sensitive sites, } \\
\text { principally in the USA }\end{array}$ & $\begin{array}{l}\text { To reveal the UK's “hidden" Ministry } \\
\text { of Defence facilities and military sites }\end{array}$ \\
\hline & News driven & Image driven & Image driven \\
\hline Institutional context & Policy analysis agency & Anti-secrecy activist & Individual hobbyist \\
\hline Geographic focus & Global & Chiefly USA & UK \\
\hline Spatial scale & $\begin{array}{l}\text { Increasing resolution over time: best } \\
\text { available and often commissioned sources }\end{array}$ & $\begin{array}{l}\text { Varies: juxtaposition of publicly } \\
\text { available sources }\end{array}$ & Varies: best available and user controlled \\
\hline Number of sites & $\begin{array}{l}1100 \text { baseline sites to } 2001 \\
\text { Unknown but huge number of subsequent } \\
\text { images }\end{array}$ & 610 eyeballs & ca 325 sites \\
\hline Sources & In-house analysis and presentation & $\begin{array}{l}\text { Anonymous informants and in-house } \\
\text { presentation }\end{array}$ & Anonymous informants and in-house presentation \\
\hline Interpretative materials & $\begin{array}{l}\text { Part of complex array of site-specific } \\
\text { evidence, including policy-relevant analysis }\end{array}$ & $\begin{array}{l}\text { Only rarely accompanied by rich } \\
\text { textual explanation }\end{array}$ & Detailed descriptive analysis explaining imagery \\
\hline $\begin{array}{l}\text { Cross referencing and } \\
\quad \text { linking }\end{array}$ & $\begin{array}{l}\text { Images associated with hyperlinked policy } \\
\text { or news briefings }\end{array}$ & Limited cross referencing & Sophisticated internal links \\
\hline Methods & $\begin{array}{l}\text { Montage of aerial photographs, } \\
\text { maps and texts }\end{array}$ & $\begin{array}{l}\text { Multimedia presentation of maps, } \\
\text { images, photographs, text and } \\
\text { hyperlinks to other documents }\end{array}$ & $\begin{array}{l}\text { Juxtaposition of map, aerial photograph and satellite- } \\
\text { based evidence. Sophisticated use of multiple image } \\
\text { sources under user control }\end{array}$ \\
\hline Usability & $\begin{array}{l}\text { Searchable, easy to find site-specific images, } \\
\text { hard to find all images }\end{array}$ & $\begin{array}{l}\text { Searchable, multiple site-specific } \\
\text { pages, organised by date }\end{array}$ & Four main pages, random arrangement, hard to use \\
\hline
\end{tabular}

\subsection{Eyeball Series}

Architects John Young and Deborah Natsios are activists and anti-secrecy archivists who run the Cryptome website. Cryptome is "an archive of spatial and geographic documents on privacy, cryptography, dual-use technologies, national security and intelligence - communicated by imagery systems: cartography, photography, photogrammetry, steganography, climatography, seismography, geography, camouflage, maps, images, drawings, charts, diagrams, imagery intelligence (IMINT) and their reverse-panopticon and counter-deception potential" (<http://cryptome.org/other-stuff. $\mathrm{htm}>$ ). Cryptome is an important node in the network of websites concerned with freedom of information, challenging powerful interests particularly in the areas of surveillance technologies, digital rights and cryptography ${ }^{3}$. It serves as an anti-secrecy web-based archive, and has been described as the world's most dangerous website (Cook, 2007).

Embedded in the site is an ongoing project consisting of a series of individual 'eyeballing' web pages, each of which focuses on views of a particular 'sensitive site'. The political agenda in creating 'eyeballs' is to show people the places that the powerful do not want the rest of the world to see (Cook, 2007). The mapping of facilities related to the United States' continued maintenance of weapons of mass destruction, for example, was released here long before Google chose to serve high-resolution imagery, and highlighted the hypocrisy of the Bush Government in relation to nuclear non-proliferation. The Eyeballing project is dedicated to revealing the murky workings of powerful organisations that wish to operate hidden away from public scrutiny. It complements the rest of the largely textual Cryptome archive.

Each eyeball presents a spatial story representing a hidden, sensitive site, encouraging the reader to actively explore and think what happens there. As of April 2009 Young has created 610 sepa-

\footnotetext{
${ }^{3}$ Others include the Federation of American Scientists (<www.fas.org $>$ ), the Memory Hole (<http://thememoryhole.org $>$ ), and the National Security Archive at George Washington University (<www.gwu.edu/ nsarchiv $>$ ).
}

rate 'eyeballing' web pages and the thematic scope of the series continues to expand. So far the Eyeball Series has covered army, airforce and naval bases, the FBI, the CIA, the National Security agencies, nerve gas storage facilities, nuclear power plants, dams, numerous little known intelligence listening posts, as well as the Kennedy Space Centre, the Statue of Liberty and the location of underground government bunkers (e.g., Fig. 1).

Guantanamo has received particular attention, with many different and frequently updated 'eyeballs' depicting the changing facilities. The private residences of some of the wealthy and powerful are also revealed: for example the Bush family ranch in Crawford, Texas, and Rupert Murdoch's New York penthouse. The majority of secret sites depicted are in the US, but the project strays sporadically outside the homeland; for example to map US military/intelligence presence in the UK, or ex-Soviet nuclear facilities, or former Stasi buildings in Germany.

'Eyeballing' exploits the potential of hypertext to author a cartographic collage, piecing together a diverse range of satellite imagery, photographs, topographic maps at different scales, photographs, along with occasional interpretative commentaries, annotated with corrections and clarifications emailed in from (usually anonymous) readers. There are also hyperlinks to supplementary documents and other relevant websites, while individual 'eyeball' pages are themselves cross-referenced by hyperlinks. To produce the 'eyeballs', Young utilises public internet sources of maps and imagery, typically topographic mapping from MapQuest, and Google Maps, supplemented with aerial photography and satellite imagery from Terraserver and the United States Geological Survey (USGS). The 'eyeballs' have an unpolished, amateurish look to them. They are presented in a simple sequential listing. Some are richly detailed, for example the page mapping out every nuclear facility in the USA. Others are brief and sometimes almost without commentary, such as a single 1984 photograph of a Cuban 'spy ship'. Eyeballing carries advertisements, which often leads to strange juxtapositions of surveillance/militaristic promotion alongside critique of this world, and also maintains a link to Alan Turnbull's Secret Bases web project detailed next. 


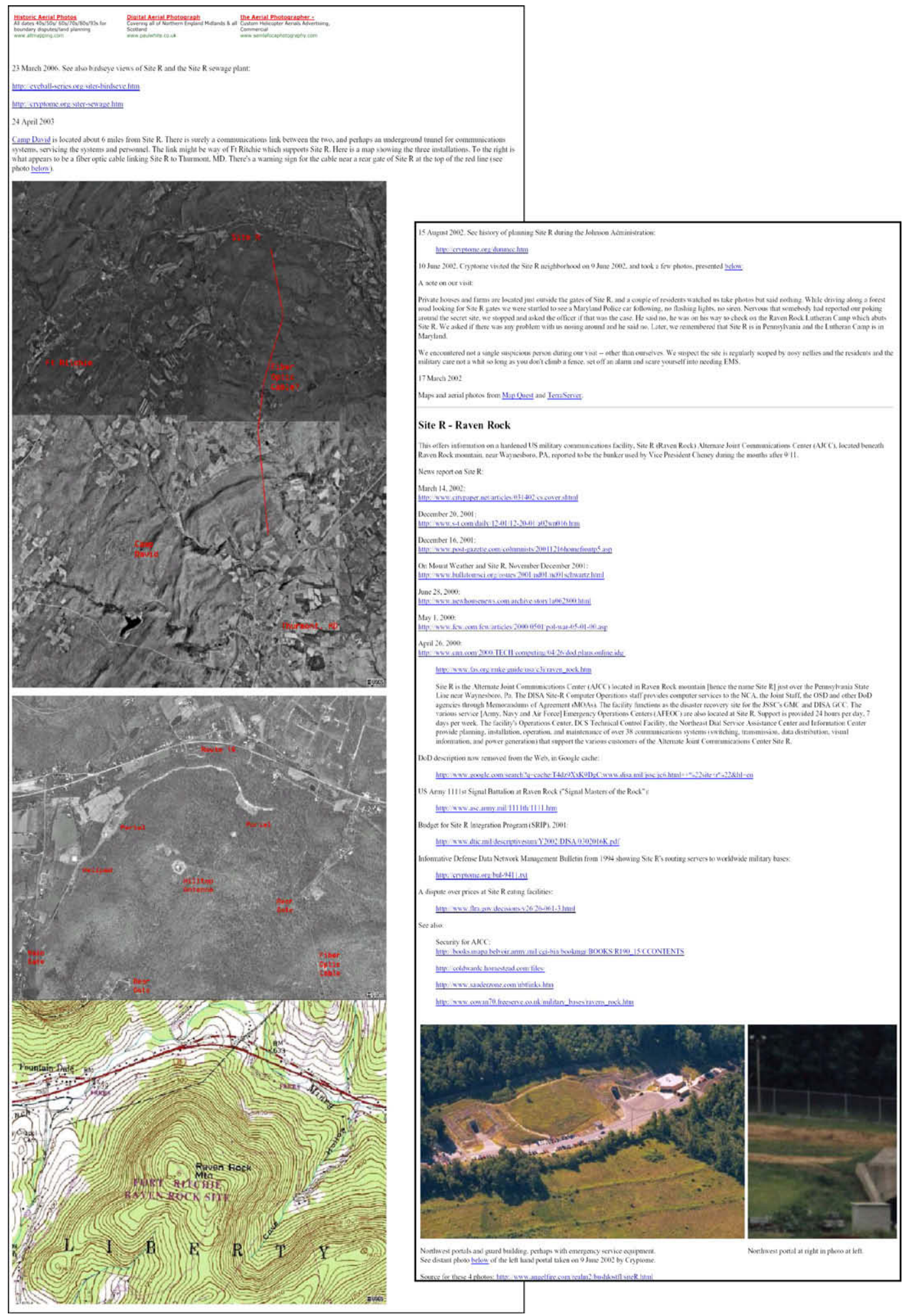

Fig. 1. Part of Eyeball Series page on “Site R - Raven Rock Governmental Bunker (originally created March, 2002, last updated October 2006), <http://eyeball-series.org/site-r/ site-r-001.htm>.

\subsection{Secret Bases}

The British government has a long-standing reputation for excessive secrecy (cf. Hennessy 2003) and this has been reflected, and in many ways reinforced, through state sanctioned mapping of the Ordnance Survey (see Hodson, 1999, pp. 157-168). Started in 2003 the Secret Bases site at first aimed to expose the extent of censorship and deliberate obfuscation in these official topographic maps: it can still be seen how some government sites were completely unmapped (replaced by the anonymity of a farmer's field in many cases); other bases were deliberately mapped incompletely to mask their size and function; whilst the purpose of other 
important sites was obscured through innocuous labels, such as 'works', 'depot' or 'disused airfield'. Remotely sensed imagery was used unambiguously as a 'mirror of reality' to expose the textual malfeasance of the mapmakers. Following a slow and gradual liberalisation in official policy in the UK towards the mapping of these sites, and the release of large scale web-served image sources, the emphasis of Secret Bases has shifted towards the documentation of sites using aerial photography and satellite imagery coverage. Whilst the project author Turnbull is distinctly an 'amateur', and in some respects a military buff 'collecting' secret bases, the site has amassed a considerable body of facts on the military geography in Britain that are not readily accessible elsewhere in the public domain.

The site only focuses upon the UK, and concentrates on military bases. Turnbull pays attention to sites that are related to Army, Royal Air Force, Royal Navy and the Intelligence Services, as well as infrastructure relating to signals interception, nuclear weapons production and storage, and military research laboratories. These sites are accessible from several scrolling main web pages, from hyperlinks embedded in extensive textual discussions. There is separate coverage focusing upon extraordinary rendition and the Trident nuclear weapons programme. In addition his research methodology and sources are well documented. Altogether in April 2009 a total of around 325 secret sites were presented in Secret Bases.

The design and information structure is somewhat more sophisticated than the Eyeball Series project. The user can choose which source to display for many of the sites. Options range from various Ordnance Survey map scales sourced from the publicly available Multi Agency Geographic Information for the Countryside (MAGIC), to the Ordnance Survey online Getamap site, the Multimap online service, Google Maps and Earth or Microsoft Live. A more recent innovation has been the use of pilot-sourced oblique aerial imagery. In some cases mapping is juxtaposed to imagery, so as to expose secrets, as the material details of unmapped building and infrastructures appear in one but not the other viewpoint (Fig. 2).

The site's tone is personal and somewhat light-hearted, including jokey 'spy' graphics and garish coloured icons; a parody of the rather po-faced and bureaucratic British approach to official secrecy, without the hard political edge of the Eyeball Series. Turnbull urges the reader to "Be intrigued, amazed, shocked, outraged - all of the above. But above all, be entertained [original emphasis] by the power of public domain information, available from open sources! Analyse my research findings and draw your own conclusions! Read on and enjoy!" (<http://homepage.ntlworld. com/alan-turnbull/cia-rendition.htm $>$ ). His site also reveals a desire to be noticed - media coverage is strongly highlighted, with top-level links to external articles written by Turnbull and also to external coverage sourced from his work.

This exposure of secret bases is developed in Turnbull's discursive commentary that accompanies the images. For example in 'revealing' the location of CIA extraordinary rendition flights in the UK (see <http://homepage.ntlworld.com/alan-turnbull/ciarendition.htm>). The Secret Bases project is cogently argued, and offers an increasingly comprehensive and regularly updated collection that demonstrates in an accessible fashion the otherwise hidden extent of military-intelligence infrastructure in Britain. Furthermore, Turnbull encourages others to use his methods of cartographic counter-analysis for themselves, claiming: "You can

\footnotetext{
${ }^{4}$ He also operates a fan site for the long running British television soap opera Emmerdale Farm and appears to revel in the publicity and 'cloak and dagger' nature of exposing supposed secrets, and meetings with the security establishment. The website is also hosted on a personal homepage service of a consumer ISP, as revealed by the URL
}

have great fun by using the Internet research tools to search for "secret sites"' (<http://homepage.ntlworld.com/alan-turnbull/ secret4.htm>).

\subsection{Public Eye}

Public Eye is an initiative developed in the mid 1990s by policy analyst John Pike. Since 2000 this initiative has been part of GlobalSecurity.org, which now markets itself over the web as "the leading source of background information and developing news stories in the fields of defense space, intelligence, WMD and homeland security" (<www.globalsecurity.org/org/overview/history.htm>). Like the Eyeball Series it draws upon satellite image sources in the public domain to reveal hitherto unknown information to wider civil society. Pike's remit, however differs from John Young's. His outward concern is primarily to increase the capacity of the non-governmental community to influence debates. The aim is to compile complete coverage of all weapon-related secret sites, with historical and contemporary image data and site profiles. As a one-stop web-based source of security data, the site has become very much part of the system that it documents, rather than serving as a critical outsider.

Pike first employed declassified Cold War CORONA imagery, together with declassified U2 aerial imagery, USGS aerial photography coverage and topographic quadrangles, or JOG graphics, alongside coarser resolution SPOT and Landsat imagery to provide context around the larger sites. From 2000 onwards Russian imagery became available from Terraserver, along with Space Imaging's IKONOS data and subsequently Quickbird imagery from Digital Globe. The most appropriate sources are used rather than following a standard pattern (see Fig. 3).

Unlike the other two projects, Public Eye has purchased a significant amount of satellite imagery rather than rely on freely available public sources.

In Public Eye these images are deployed in two complementary programmes. A baseline campaign documented the global inventory of special weapons and related facilities, displaying images of facilities ranging in scale from individual structures up to large areas and displaying imagery of 1100 facilities by mid-2000. Higher resolution imagery has been deployed in the priority campaign focusing attention on the newer or more opaque facilities, in particular those outside the USA. Online profiles describe existing facilities and the development of a site and are accompanied by maps, imagery and often ground level photographs. Images are almost always interpreted, if only by caption (see Fig. 4).

They may be accessed from a Public Eye section of the website that focuses upon imagery, organised on an image a week basis, or from thematic information organised under the headings Military, WMD, Homeland and Space, or from a keyword search system. These 'Pictures of the Week' (archived from 2001 to 2006) feature timely stories that are placed on images, with sufficient precision to elucidate an event, usually with an accompanying storyline and often with captions. Later imagery on the site is almost all sourced from Digital Globe, and has started to use Flash-based animated explanations of the story line. Access to imagery now depends upon the news narrative, rather than an image search per se: it is hard to identify just how many images are available on the site.

The content is disseminated at no cost, but a significant array of commercial adverts are juxtaposed with the imagery. In stark contrast to the Eyeball Series the impression is of a slick, fast, commercial web environment. Harris (2005, p. 18) argues that Pike's work is best understood as part of a realist narrative of transparency that provides "both the narrative structure and the techno-discursive anchor for satellite imagery systems in the social and cultural 

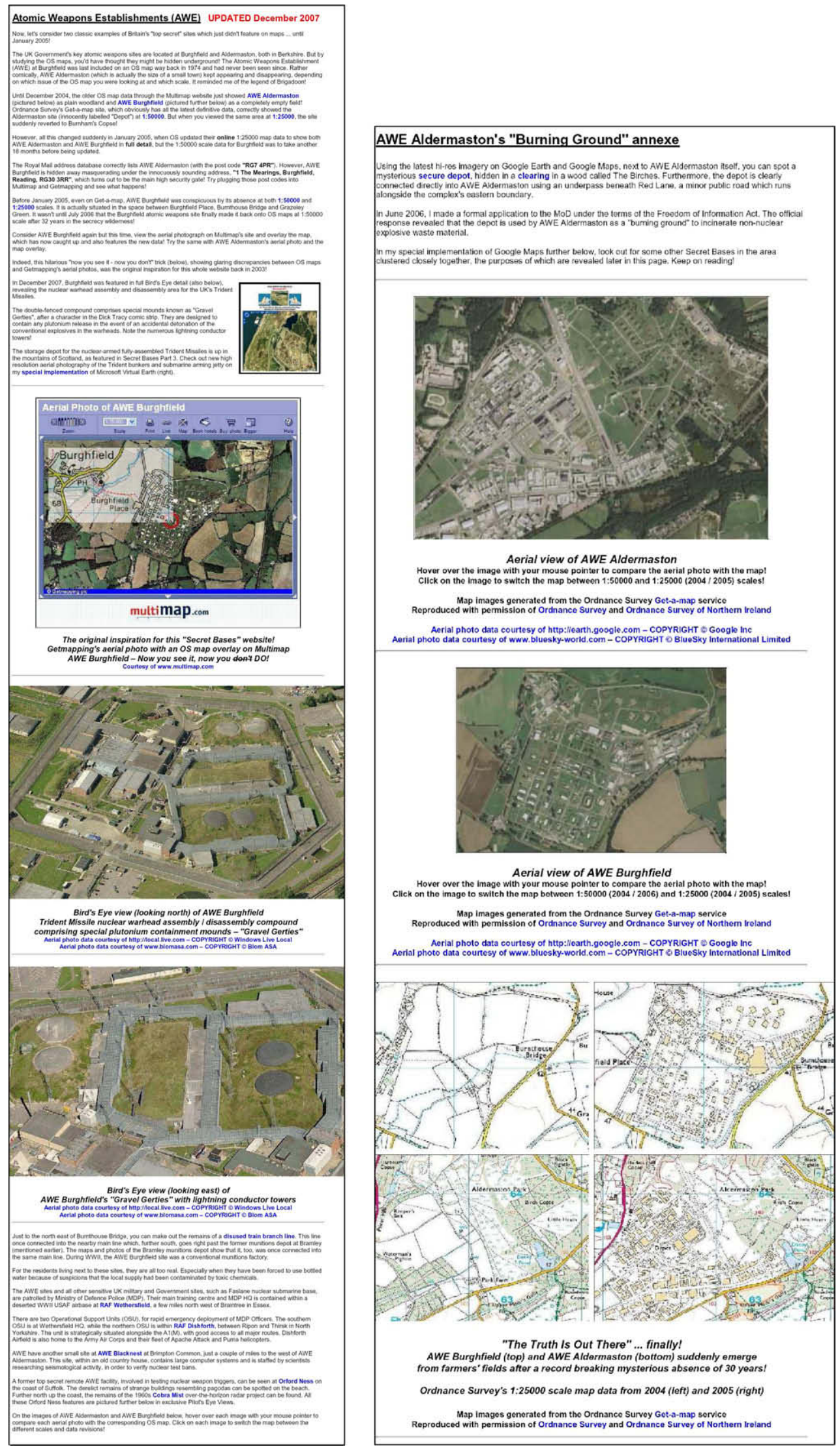

Fig. 2. Part of Secret Bases using contrasting imagery and maps for the same area from different dates to exposes the unmapped status of Britain's nuclear weapons factories, $<$ http://homepage.ntlworld.com/alan-turnbull/secret2.htm\#atomic>. 


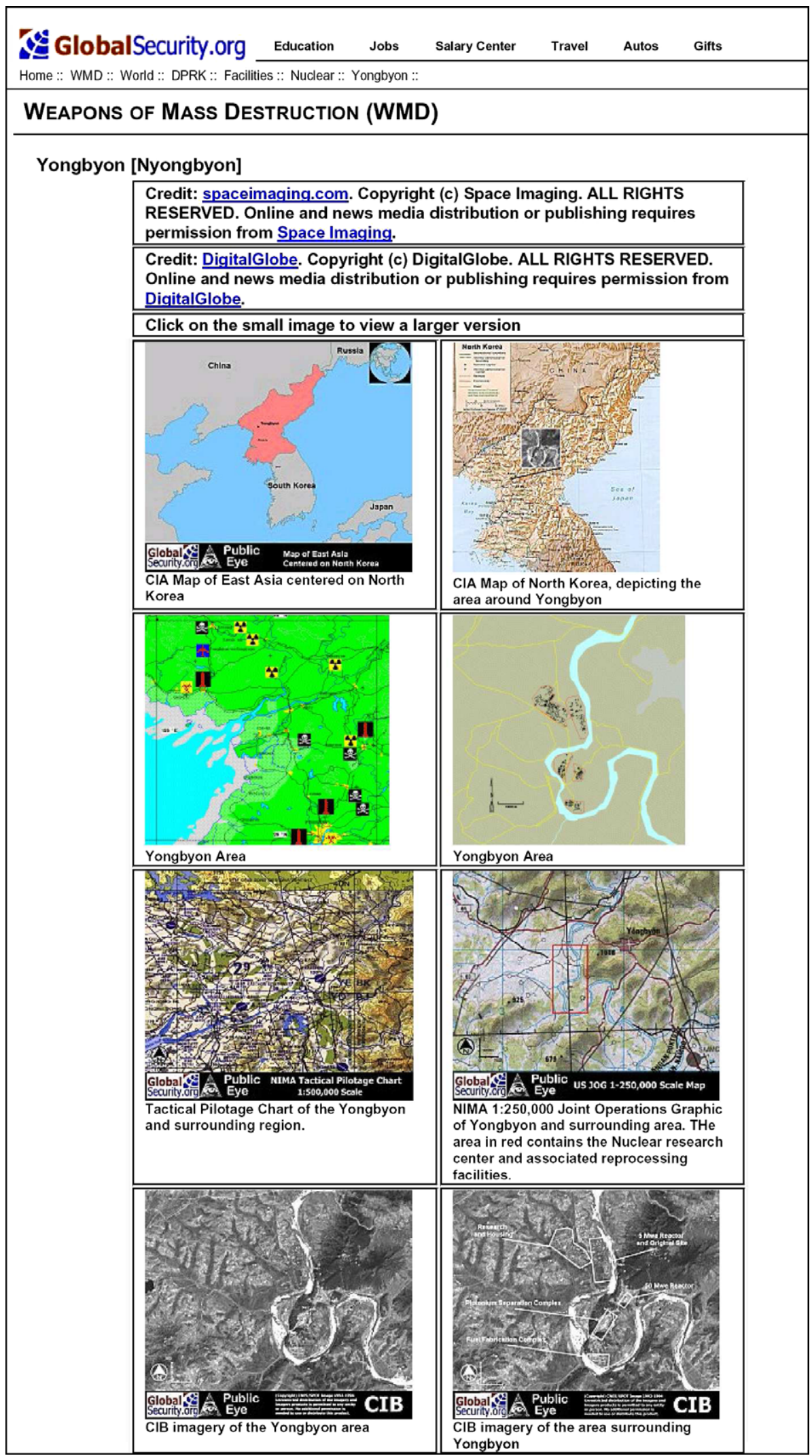

Fig. 3. Part of Public Eye page on North Korea's Yongbyon nuclear facilities (December 2002), <www.globalsecurity.org/wmd/world/dprk/yongbyon-imagery.htm>.

mindset". GlobalSecurity.org situates imagery into a narrative aimed at news organisations, existing, former and potential members of the military, defence contractors, congressional staff, academics, students and the wider public. The emphasis of this market is primarily US. The site claims to serve 500,000 page views each day and only $20 \%$ of the 2.5 million monthly visitors are repeat users (<http://www.globalsecurity.org/org/overview/audiences.htm>). 


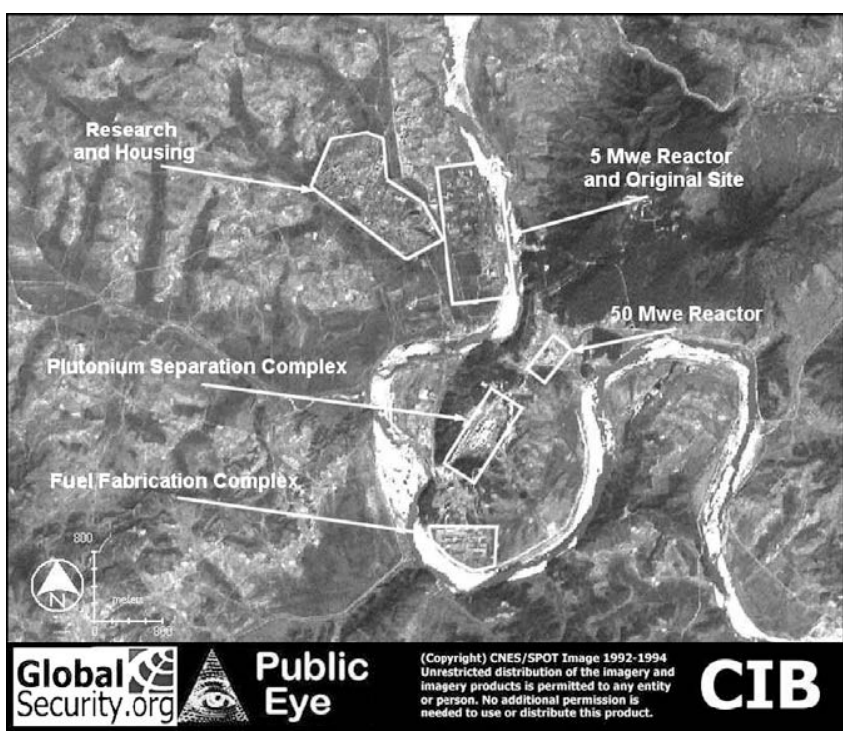

Fig. 4. Image with annotations from Public Eye page on North Korea's Yongbyon nuclear facilities (December 2002), <www.globalsecurity.org/wmd/world/dprk/ images/yongbyon-cib1.jpg>.

So Public Eye is embedded in a website with a much more mainstream and commercial agenda than the previous two projects considered - whose remit is to provide quick access to breaking stories, and background reference material in multi-mediated format. For the organisation to thrive and grow it must be authoritative and appear neutral, but for this to happen advertising revenue is also required. Pike features whatever story is high on the news agenda. Whilst US bases feature in the site (and very strongly in the WMD section), the weapons programmes of North Korea, Pakistan, Israel and Iran are of equal concern. Coverage is impressively global. The aim is better policy and more open government, rather than critique alone.

\section{Discussion}

Examining the kinds of counter-hegemonic challenges they offer can help to assess the significance of these three web-based projects, and how a narrow aspect of visual culture contributes to a wider climate of generalised secrecy. Clearly each project seeks to question state secrecy with somewhat different objectives, yet their direct impact on public consciousness and the activities of government agencies is less clear. They all provide a new vision that stimulates the imagination and hints at more than can actually been seen, making the viewer feel somehow illicit in looking straight down onto some of the most secure and sensitive places on earth. They affect a thrill at seeing things you are 'not meant to see', that are for authorised eyes only. They all trade on spectacular secrecy: were the sites they depict not in some way secret then the rationale for these web projects would be lost. The maps and satellite imagery are entirely conventional, legal and publicly available: in that sense they each offer a Debordian détournement (Vidler, 2006) and the subversive feeling is created through the focused selection and unconventional arrangement of maps, images, interpretation and commentary. Each project consciously targets the secret sites, but this targeting would have no purpose were the sites fully open to public scrutiny. So any analysis of their significance has to recognise the ambivalent nature of the process of revealing secrets.

The matter-of-fact style of much of the satellite imagery and cartographic information presented in these projects is useful to challenge the myths that grow around secrecy. The Eyeball Series in particular helps to 'ground' otherwise murky, anonymous and deliberately intimidating institutions, when one can see that they inhabit ordinary office buildings, in a beltway sprawl around Washington DC for example (see Natsios, 2005; Paglen, 2009, for consideration of the opaque post-9/11 national security apparatus in the Washington DC). It begins to reel them back into our everyday reality from some kind of X-Files fringe. So this kind of mapping dissolves mystery, trading on Haraway's (1988) disembodied view from nowhere, but also invites a questioning of the power of the unannounced infrastructure around us. A similar affect is produced by the different authorial approach on Secret Bases: here a more satirical and light-hearted style pokes fun at the absurdities of official secrecy, in a particularly British context. But the affect of the different projects also reveals something of their owners: an acerbic, and perhaps even paranoid, tone emerges from the Eyeballing project website, as well as from interviews with John Young (e.g. Cook, 2007). A tone that is very much at home in the world of spectacular secrecy of the 'New Normal', where everything has the potential to be covered up, and where discovering conspiracy and clandestine activity has become a matter of everyday practice (Bratich, 2006; Paglen, 2009).

Even very detailed maps and images, however, can only tell us so much. These projects are working within the constraints of available public spatial data sources, which are often partial and out of date. Military analysts almost certainly work with data that are more current and fit to purpose. They can commission new scenes to be captured, or employ experts to use sophisticated image analysis software to extract patterns from the visual complexity of a scene. In contrast public data sets may lack essential metadata. The Eyeball Series and Secret Bases are especially hampered by this dating problem. Also image resolution varies across the globe: of the case studies only the policy analysts consistently acquire dated, high-resolution imagery ${ }^{5}$. The apparent availability of formally secret data may then simply hide a more sophisticated mechanism for preserving secrecy, with access to these inferior data being tolerated, in order to maintain military and state control over the superior and secret resolutions. Revealing new secrets simply leads to other secrets being perpetuated (Debord, 1998).

The nature of each of the project designs and interfaces also limits their power to critique. None of the projects claim to offer a complete evaluation of secrecy. All select, but the nature of the selection process is not always at all clear. New secrets are made in the very process of revealing (Bratich, 2006). Public Eye offers the most comprehensive global coverage, but often only through other headings on the GlobalSecurity.org website. Secret Bases is progressively building an impressive national coverage of its rather limited spatial and thematic remit. The Eyeball Series is much more eclectic and random in its coverage.

Site sophistication varies and limits the kinds of uses that may be made of the counter-mappings provided. The extent of hyperlinking differs and so does the nature of search capability. The Eyeball Series only offers a crude listing of sites by date, supplemented with a Google-based search engine. Public Eye also focuses upon timing of events as the prime way in to reveal secrecy along with a Google search. In contrast Secret Bases is more graphically sophisticated, allowing the user to switch between different public domain map and image datasets, including Google Earth and Microsoft's Virtual Earth mash-ups with user controlled layers to highlight key sites ${ }^{6}$. However, all three sites can also appear rather

\footnotetext{
5 In 2008 the Eyeball Series project started to acquire imagery with the purchase of a Digital Globe image of central Baghdad (see <http://cryptome.org/baghdadgz.htm>).

${ }^{6}$ See <http://homepage.ntlworld.com/alan-turnbull/trident-missiles.htm> for a recent analysis of Trident missile dispositions around the Faslane Naval base in Scotland.
} 
amateur and 'strategic site-based'. If you want to find out what is dangerous near to your own backyard these projects are of only limited use. Overview maps to allow a consistent or progressive zooming in or out, that might reveal context or association, are not presented on any of these sites. The paradoxical consequence is that all the case studies present a strangely atomized view of a secret world of isolated sites, and that the counter-politics they call into being are as a consequence very limited in their direct capacity to resist. They focus attention on a specific placing of secrecy, rather than its ubiquity. Debordian spectacular and general secrecy dictates their existence (Bratich, 2006, 2007), but their authorship denies anything beyond their immediate concerns. It almost suggests a celebration of the possibilities of the web technology and new satellite imagery without regard to the wider politics of what they do, and as such has much in common with underlying attitudes of the militaryindustrial-security complex. The oppositional projects and the hegemonic complex both seem to celebrate techno-scientific fantasies of total surveillance and both fetishise the latest weapons and technologies.

Each of the projects uses visual technologies to reveal secrecy, and so each mainly resorts to a strongly dehumanised and distanced view. They replicate the 'god trick', and perhaps reinforce the importance of an objectivist, surveillant geographical imaginary, instead of offering a more embodied alternative (Pickles, 2004). Places are mostly mapped without people or feelings. The Eyeball Series does seek to personalise secrecy, by focusing on individuals' roles in the production of secret power and (for some stories) including photographs of individuals, in a 'bricolage' of different media (see Fig. 5).

Secret Bases also sometimes personalises the practice of spying, but rarely the practices or feelings of people in the sites themselves. A more personal critique such as that offered by Paglen's artistically driven practices $(2006,2009)$ is, perhaps, less likely to be tainted by the power of the gaze.

This stylistic and functional shortcomings are exacerbated by the limited focus of the projects: they only scratch the surface of what is going on at these hidden and sensitive places. The glimpses of visible structures only give a limited sense of the implications of what is being performed daily. Viewers must rely upon the interpretative commentary to understand the image, in the same way that Parks (2001) describes the limits and power of imagery of Bosnia in news broadcasts. Outsiders, who must rely upon public domain sources, construct critical commentary. Dehqanzada and Florini (2000, p. 8) acknowledge that "[i]t takes years before an analyst gains the experience and expertise necessary to be able to derive useful information from gigabytes of transmitted data." Experience in recognising troop movements differs from expertise in recognising nuclear testing or in environmental assessment. These skills are largely the preserve of the establishment, not the critics. Only Public Eye offers really detailed political interpretation, and this is often tied to specific news narratives, rather than offering a systematic documentation of the site. On the other hand the other two projects each rely upon a growing community of activists, whose interpretations and rumours are disseminated through the projects, for example, the 2008 identification of aircraft involved in extraordinary rendition flights on the Secret Bases website. So the direct counter-hegemonic challenge of all three sites is necessarily constrained by their format and institutional context.

Nor can the interconnections, flows and chains of command, vital to the working of many hidden places, be observed in static images of facilities. By focusing on containers not practices these projects tend to replicate the notion that space can be seen and understood as a set of structures such as fences, buildings, or fixed marks on a map, rather than a set of social practices that are performed in particular places to beckon spaces into being.
All three projects therefore tend to reinforce the view of secrecy as the dark opposite of publicity, at the same time as they also make newly secret knowledge. Photographs, topographic maps and satellite imagery can only hint at the nature of power, they cannot actually show us power relationships. Florini (1998, p. 60) observes that for secret sites "[t]ransparency reveals behavior, but not intent." The visual media consciously employed on these sites offer only a limited gaze into the multi-sensory world of spectacular secrecy. In practice secrecy is experienced, and practised as a process: hearing gossip, talking and taking embodied action as well as simply seeing a site, diffuses secrets. Seeing a disembodied image on a screen only reveals a part of the secret world. It does not in itself directly challenge the power of those who operate these facilities.

Moreover, organisations with something really worth hiding often put their most sensitive sites fully underground. Maps and images showing access roads and entrance portals to bunker complexes only give the barest hint of their subterranean extent. Also nowadays much of the secret work of the military and intelligence community is actually transacted in cyberspace, in the data networks, servers and webs of encrypted information flows, which are completely invisible to conventional cartographic display of physical facilities. With the growing recognition that detailed vision is no longer restricted it is likely there will be more attempts to conceal secret sites, as more organisations realise the capability of satellite observation.

Consequently, we should not be naïve about the critique offered in the case studies. The visual medium may imply evidential transparency, but selection, interpretation and context reveal the very positioned and largely unaccountable nature of the critique. Florini (1998, p. 61) argues NGOs and activists are "unelected, unaccountable, and sometimes less transparent than the institutions they monitor"; nor do they offer any "guarantee of action or progressive change". Whilst the case studies would claim their work advances the cause of open government it could be argued that Public Eye merely accentuates the newsworthy in order to increase its market share, that the Eyeball Series is too removed from the policies of secrecy revealed in its sister site Cryptome and too overtly activist to be taken seriously, and that Secret Bases is a train-spotting-like listing exercise.

Whilst the case studies offer new views there is little evidence of the cultural impact of the critique. GlobalSecurity.org lists impressive numbers of hits on its website, but the military advertising and marketing of the site suggest only a small percentage of these users are concerned with critique. The Eyeball Series does not publish records of the number of hits. Secret Bases claimed over 1.2 million hits to its site in April 2009, but many of these are likely to be to its Emmerdale Farm fan site. There is indirect evidence of cultural impact in the form of reaction. The Eyeball Series and Cryptome have been a clear concern to the U.S. establishment since 9/11. For example, early in 2005 Readers' Digest ran a strongly critical article attacking web-based, security breaches, and focused on Young's Eyeball Series website (Crowley, 2005). The article described the site as dangerous and irresponsible and juxtaposed an attack on open government with a cartoon featuring an Islamist viewing a website and proclaiming "Site Maps, Security Overrides, Suggestions. Download Now! It's Safe - It's Easy - It's Protected by the Constitution." Young has been visited by agents from MI6 and the FBI, asking him to remove material, and has had to move his ISP after official pressure to remove his sites from their servers (Cook, 2007). The voices of the right-wing political establishment in the US clearly think sites such as the Eyeball Series threaten their agenda. In the UK, Turnbull's exposure of cartographic silences is strongly compatible with recent UK-based campaigns against excessive monopoly control of spatial data, such as the Guardian Newspapers' Free 

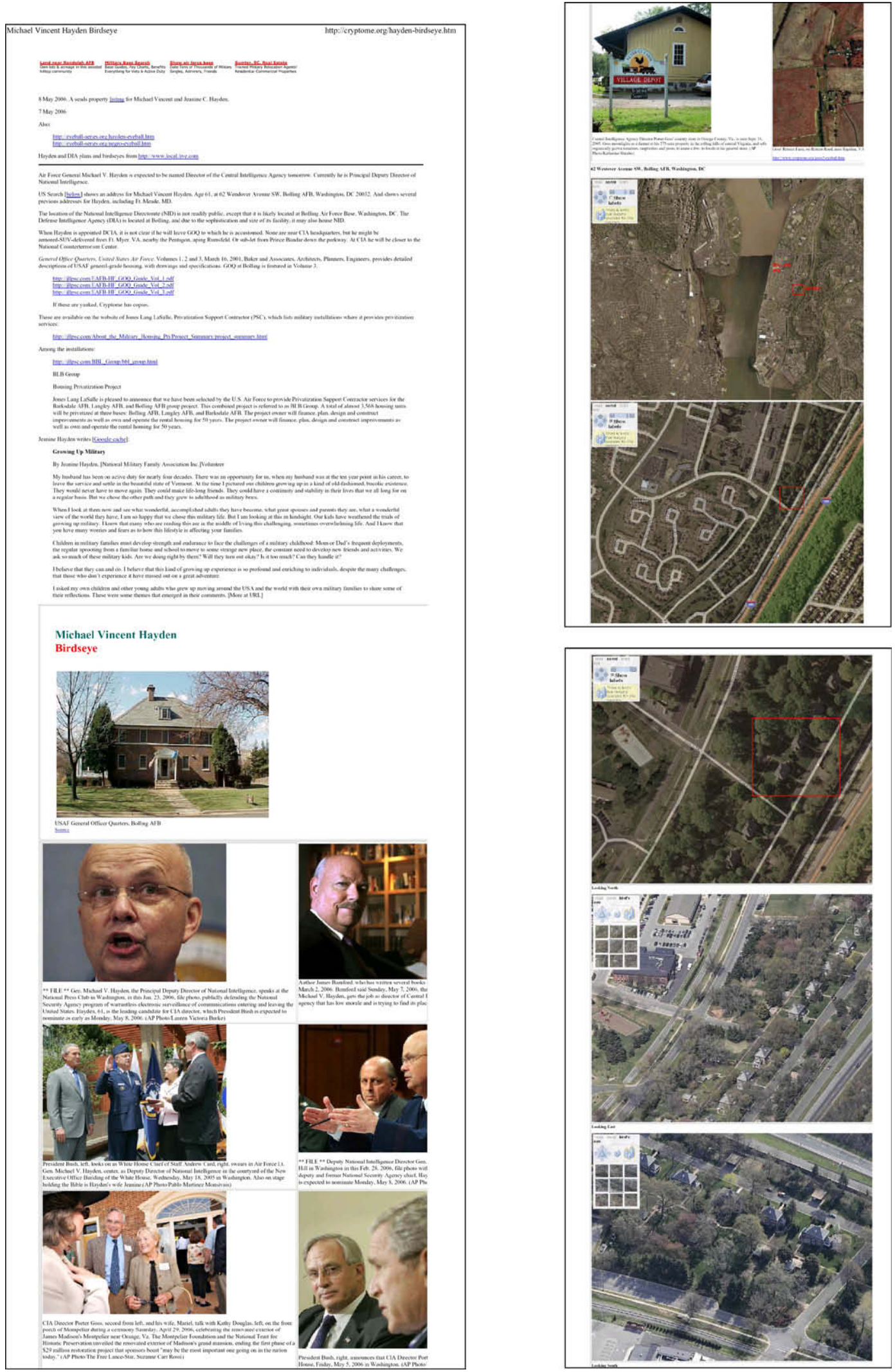

Fig. 5. Part of Eyeball Series page on Michael Hayden, CIA director (May 2006), <http://eyeball-series.org/hayden/hayden-birdseye.htm>.

Our Data Campaign (2009) and the latest revisions of Ordnance Survey maps are beginning to reveal formally hidden and unmapped sites (see Fig. 2). He has been invited several times by the media to comment on matters of official secrecy and has built contacts inside the security establishment. Once again the play of spectacular secrecy reveals complex inter-relationships between 
the worlds of those revealing, and those charged with preserving secrecy, instead of any notion of binary opposition.

\section{Conclusions}

Dean (2002) argues that the internet widens public demands for information but also strongly supports media industry interests that are cynically reinforced by contemporary techno-culture. Accordingly democracy becomes just another spectacle, as publicity and secrecy become intertwined in political imaginaries and media conspiracies. Assertions of 'openness' have become co-opted by consumption capitalism, which depends upon secrets for its rhetorical power and, paradoxically, is itself implicated in hiding information.

Thus the vast profusion of openness offered by satellite imagery served from Google and other online image services cloaks secret places, which are embedded with so much data that the needle of the secret site cannot be seen amidst the vast, 'open' image haystack. Availability of imagery on the Internet does not mean information about secret sites is available to all, or automatically revealed, let along being acted upon to effect change. However and paradoxically the counter-mapping case studies presented in this paper, which only give a 'pin-hole' view into the world of secret and sensitive sites may also have limited counter-hegemonic power. There are dangers in exaggerating their cultural impact as well. They clearly offer a disruptive view, and being freely distributed through the web, it could be argued that these 'eyeballs' are potent maps of resistance to the growing secret state. They focus attention on sites that would otherwise be lost in space. We would argue, however, in contrast to Natsios and Young (2001) that they do not really reverse the panoptic tools of the watchers. Rather they form part of a much wider democratising process, offering newly secret information, part of the interplay of post 9/11 cultural politics, but mediated by the nature of the internet and the culture of their projects. In an era of spectacular secrecy they offer a fractured view, rather than a wholesale reversal of secrecy - as Bratich (2006, p. 42) observes "... the moment of revelation did not end secrecy, but intensified and redistributed it." We would argue that they are better thought of as analogous to other cultural and political 'jams' delineated by Cammaerts (2007), articulating different voices and deploying images from visual culture in new ways, a partial, personal and often egocentric intervention into counter-hegemonic politics, not an explicit or revolutionary challenge to power. The three projects considered here do not pretend to reveal everything; their voices are themselves positioned; they articulate new kinds of secret knowledge; but they are limited by the very visual medium that they deploy. Indeed they show how vision is itself positioned, that the balance between secrecy and publicity is ambivalent and intensely political, and that cultural practices of knowledge production and dissemination are important in the construction of oppositional discourse.

\section{References}

Aday, S., Livingston, S., 2009. NGOs as intelligence agencies: the empowerment of transnational advocacy networks and the media by commercial remote sensing in the case of the Iranian nuclear program. Geoforum 40 (4), 514-522.

Baker, J.C., Williamson, R.A., 2006. Satellite imagery activism: sharpening the focus on tropical deforestation. Singapore Journal of Tropical Geography 27, 4-14

Baker, J.C., O'Connell, K.M., Williamson, R.A., 2001. Commercial Observation Satellites: At the Leading Edge of Global Transparency. RAND, Santa Monica, CA.

Banisar, D., 2004. Freedom of Information and Access to Government Record Laws Around the World. <www.freedominfo.org/documents/global_survey2004.pdf>.

Beck, R.A., 2003. Remote sensing and GIS as counterterrorism tools in the Afghanistan war: a case study of the Zhawar Kili region. Professional Geographer 55 (2), 170-180.

Biemann, U., 2002. Remotely sensed: a topography of the global sex trade. Feminist Review 70, 75-88.
Birchall, C., 2007. Introduction. Cultural Studies 21, 1-4.

Board, C., 1991. Things maps won't show us: reflections on the impact of security issues on map design. In: Rybaczuk, K., Blakemore, M. (Eds.), Mapping the Nations, Proceedings of the International Cartographic Associations 15th Conference, vol. 1. pp. 136-148.

Bratich, J., 2006. Public secrecy and immanent security. Cultural Studies 20 (4-5), 493-511.

Bratich, J., 2007. Popular secrecy and occultural studies. Cultural Studies 21 (1), 4258.

Bunge, W., 1971. Fitzgerald: Geography of a Revolution. Schenkman, Cambridge Mass.

Cammaerts, B., 2007. Jamming the political: beyond counter-hegemonic practices. Continuum: Journal of Media and Cultural Studies 21 (1), 71-90.

Cloud, J., 2002. American cartographic transformations during the Cold War. Cartography and Geographic Information Science 29 (3), 261-282.

Cloud, J., Clarke, K., 1999. Through a shutter darkly: the tangled relationships between civilian, military and intelligence remote sensing in the early US space program. In: Reppy, J. (Ed.), Secrecy and Knowledge Production. Cornell University, Ithaca, NY, pp. 41-56.

Cook, J., 2007. Secrets and Lies: The Man behind the World's Most Dangerous Website. Radar Magazine, August. <www.radaronline.com/from-themagazine/ 2007/08/cryptome_john_young_radar_anthony_haden_guest_1.php>.

Crowley, M., 2005. Let's Shut Them Down: These Websites are an Invitation to Terrorists. Readers' Digest March, pp. 33-35.

Day, D.A., Logsdon, J.M., Latell, B., 1998. CORONA and the revolution in mapmaking. In: Day, D.A., Logsdon, J.M., Latell, B. (Eds.), Eye in the Sky: The Story of the Corona Spy Satellites. Smithsonian Institution Press, Washington DC, pp. 200-214.

Dean, J., 2002. Publicity's Secret: How Technoculture Capitalizes on Democracy. Cornell University Press, Ithaca, NY.

Debord, G., 1967. Society of the Spectacle. Black and Red, Detroit.

Debord, G., 1998. Comments on the Society of Spectacle. Verso, London.

Dehqanzada, Y.A., Florini, A.M., 2000. Secrets for Sale: How Commercial Satellite Imagery Will Change the World. Carnegie Endowment for International Peace, Washington DC

Deleuze, G., Guattari, F., 1987. A Thousand Plateaus (trans. B. Massumi. University of Minnesota Press, Minneapolis.

Florini, A., 1998. The end of secrecy. Foreign Policy 111, 50-63.

Free Our Data, 2009. Free our Data: Make Taxpayers' Data Available to Them. The Guardian. <http://freeourdata.org.uk/>.

Gramsci, A., 1971. Selections from the Prison Notebooks of Antonio Gramsci. Lawrence and Wishart, London.

Haggerty, K.D., Ericson, R.V., 2000. The surveillant assemblage. British Journal of Sociology 51 (4), 605-622.

Haines, L., 2007. Google Erases British Bases in Iraq. The Register 17 January. <www.theregister.co.uk/2007/01/17/google_erases_brit_bases/>.

Haraway, D., 1988. Situated knowledges: the science question in feminism and the privilege of partial perspective. Feminist Studies 14 (3), 575-599.

Harding, T., 2007. Terrorists 'Use Google Maps to Hit UK Troops'. The Daily Telegraph 13 January. <www.telegraph.co.uk/news/worldnews/1539401/ Terrorists-'use-Google-maps-tohit-UK-troops'.html>.

Harley, J.B., 1988. Maps, knowledge and power. In: Cosgrove, D., Daniels, S. (Eds.), The Iconography of Landscape. Cambridge University Press, Cambridge, pp. $277-312$.

Harley, J.B., 1989. Silences and secrecy: the hidden agenda of cartography in early modem Europe. Imago Mundi 40, 57-76.

Harris, C., 2005. Technology and Transparency as Realist Narrative. Mimeo. <http:// communication.ucsd.edu/people/Chad-alumni/STHVpaper_web.pdf $>$.

Harris, C., 2006. The omniscient eye: satellite imagery, battlespace awareness, and the structures of the imperial gaze. Surveillance and Society 4 (1/2), 102-122.

Harris, L.M., Hazen, H.D., 2005. The power of maps: counter-mapping for conservation. ACME: International E-Journal for Critical Geographies 4 (1), 99-130.

Hennessy, P., 2003. Secret State: Whitehall and the Cold War. Penguin, London.

Hodson, Y., 1999. Popular Maps: The Ordnance Survey Popular Edition One-Inch Map of England and Wales, 1919-1926. The Charles Close Society, London.

Howe, J., 2006. The Rise of Crowdsourcing. Wired Magazine June 14 (6). $<$ www.wired.com/wired/archive/14.06/crowds.html>

Keefe, P.R., 2006. I spy. Wired Magazine February 14 (2). <www.wired.com/wired/ archive/14.02/spy_pr.html>.

$\mathrm{Ku}$, A.S., 1998. Boundary politics in the public sphere: openness, secrecy and leak. Sociological Theory 16 (2), 171-192.

Litfin, K.T., 1997. The gendered eye in the sky: a feminist perspective on earth observation satellites. Frontier: Journal of Women Studies xviii (2), 26-47.

Livingston, S., Robinson, L.W., 2003. Mapping fears: the use of commercial highresolution satellite imagery in international affairs. Astropolitics 1 (2), 3-25.

Mack, P.E., 1990. Viewing the Earth: The Social Construction of the Landsat Satellite System. MIT Press, Cambridge, MA.

McHaffie, P.H., 1995. Manufacturing metaphors: public cartography the market and democracy. In: Pickles, J. (Ed.), Ground Truth: The Social Implications of Geographic Information Systems. Guilford, New York, pp. 171-195.

Mogel, L., Bhagat, A., 2007. An Atlas of Radical Cartography. Journal of Aesthetics and Protest Press, Los Angeles.

Monmonier, M., 2002. Spying With Maps: Surveillance Technologies and the Future of Privacy. University of Chicago Press, Chicago.

Monmonier, M., 2005. Cartography: distortions, world-views and creative solutions. Progress in Human Geography 29 (2), 217-224. 
Mouffe, C., 1999. Deliberative democracy or agonistic pluralism? Social Research 66 (3), 746-758.

Natsios, D., 2005. National security sprawl. AD Architectural Design 75 (6), 80-85. Natsios, D., Young, Y., 2001. Reversing the panopticon. In: Tenth USENIX Security Symposium. Washington, DC. <http://cartome.org/reverse-panopticon.htm>.

Paglen, T., 2006. Late September at an undisclosed location in the Nevada desert. Cultural Geographies 13, 293-300.

Paglen, T., 2009. Blank Spots on the Map: The Dark Geography of the Pentagon's Secret World. Dutton, New York.

Paglen, T., Thompson, A.C., 2006. Torture Taxi: On the Trail of the CIA's Rendition Flights. Melville House, Hoboken.

Parks, L., 2001. Satellite views of Srebrenica: tele-visuality and the politics of witnessing. Social Identities 7 (4), 585-611.

Parks, L., 2009. Digging into Google earth: an analysis of "crisis in Darfur". Geoforum 40 (4), 535-545.

Parry, R.B., Perkins, C.R., 2000. World Mapping Today. Bowker Saur, London.

Perkins, C., 2006. Mapping. In: Douglas, I., Huggett, R.J., Perkins, C. (Eds.), Companion Encyclopaedia of Geography, 2nd ed. Routledge, London, pp. 557573.

Pickerill, J., 2006. Radical politics on the web. Parliamentary Affairs 59 (2), 266-282.

Pickles, J., 1991. Geography, GIS, and the surveillant society. Papers and Proceedings of the Applied Geography Conferences 14, 80-91.

Pickles, J., 1995. Ground Truth: The Social Implications of Geographic Information Systems. Guilford, New York.

Pickles, J., 2004. A History of Spaces: Cartographic Reason. Mapping and the GeoCoded World. Routledge, London.

Pinder, D., 1996. Subverting cartography: The situationists and maps of the city. Environment and Planning A 28 (3), 405-427.
Postnikov, A.V., 2002. Maps for ordinary consumers versus maps for the military: double standards of map accuracy in Soviet cartography, 1917-1991. Cartography and Geographic Information Science 29 (3), 243-260.

Richelson, J.T., 1998. Scientists in black. Scientific American 278 (2), 48-55.

Richelson, J.T., 2003. Eyes on Saddam: US Overhead Imagery of Iraq. National Security Archive Electronic Briefing Book No. 88. <www.gwu.edu/ nsarchiv/ NSAEBB/NSAEBB88>.

Robbins, P., 2003. Beyond ground truth: GIS and the environmental knowledge of herders, professional foresters, and other traditional communities. Human Ecology 31 (2), 233-253.

Roberts, S.M., Schein, R.H., 1995. Earth shattering: global imagery and GIS. In: Pickles, J. (Ed.), Ground Truth: The Social Implications of Geographic Information Systems. Guilford, New York, pp. 171-195.

Rogoff, I., 2000. Terra Infirma: Geography's Visual Culture. Routledge, London. Stoney, W.E., 2008. ASPRS Guide to Land Imaging Satellites. American Society for Photogrammetry and Remote Sensing. <www.asprs.org/news/satellites/>.

Tombs, R.B., 2005. Policy review: blocking public geospatial data access is not only a homeland security risk. URISA Journal 16 (2), 49-51.

Vidler, A., 2006. Terres Inconnues: Cartographies of a landscape to be invented. October 115, 13-30.

Warf, B., Grimes, J., 1997. Counter-hegemonic discourses and the Internet. The Geographical Review 87, 259-274.

Williams, R., 1977. Marxism and Literature. Oxford University Press, Oxford.

Wood, D., Fels, J., 2008. The Natures of Maps. University of Chicago Press, Chicago

Woodward, R., 2005. From military geography to geographies of militarism. Progress in Human Geography 29 (6), 718-740.

Zellmer, L., 2004. How homeland security affects spatial information. Computers in Libraries 24 (6-8), 37-40. 